\title{
Childhood Malignant Liver Neoplasm
}

National Cancer Institute

\section{Source}

National Cancer Institute. Childhood Malignant Liver Neoplasm. NCI Thesaurus. Code C7708.

A malignant neoplasm of the liver developed in childhood. Representative examples include hepatoblastoma, undifferentiated (embryonal) sarcoma, and extrarenal rhabdoid tumor. 